Research Paper

\title{
A Randomized Clinical Trial of Nefopam versus Ke- torolac Combined With Oxycodone in Patient- Controlled Analgesia after Gynecologic Surgery
}

\author{
Boo-Young Hwang, Jae-Young Kwon ${ }^{\bowtie}$, Do-Won Lee, Eunsoo Kim, Tae-Kyun Kim, Hae-Kyu Kim \\ Department of Anesthesia and Pain Medicine, Biomedical Research Institute, Pusan National University Hospital, Busan, Republic of Korea
}

$\triangle$ Corresponding author: Jae-Young Kwon, Department of Anesthesia and Pain Medicine, Biomedical Research Institute, Pusan National University Hospital, 179 Gudeok-ro, Seo-gu, Busan 602-793, Republic of Korea. Tel: +82-51-240-7399; Fax: +82-51-242-7466; E-mail: jykwon@pusan.ac.kr

(c) 2015 Ivyspring International Publisher. Reproduction is permitted for personal, noncommercial use, provided that the article is in whole, unmodified, and properly cited. See http://ivyspring.com/terms for terms and conditions.

Received: 2015.02.09; Accepted: 2015.07.18; Published: 2015.07.30

\begin{abstract}
Objectives: Nefopam is a centrally-acting non-opioid analgesic, which has no effect on bleeding time and platelet aggregation. There has been no study about nefopam and oxycodone combination for postoperative analgesia. In this study, we present efficacy and side effects of nefopam/oxycodone compared with ketorolac/oxycodone in patient-controlled analgesia (PCA) after gynecologic surgery.

Methods: 120 patients undergoing gynecologic surgery were divided randomly into two groups: Nefopam group treated with oxycodone $1 \mathrm{mg}$ and nefopam $1 \mathrm{mg}$ bolus; and Ketorolac group treated with oxycodone $1 \mathrm{mg}$ and ketorolac $1.5 \mathrm{mg}$ bolus. After the operation, a blinded observer assessed the pain with a numeric rating scale (NRS), infused PCA dose and sedation score at 1, 4, 24, and $48 \mathrm{~h}$, nausea, vomiting, headache, shivering, pruritus and delirium at 6, 24 and $48 \mathrm{~h}$, and satisfaction at $48 \mathrm{~h}$ after the operation.

Results: Nefopam group showed less nausea than Ketorolac group within $6 \mathrm{~h}$ after the operation. There were no significant differences in demographic data and other complications between both groups. At $48 \mathrm{~h}$ after operation, satisfaction and the infused PCA volumes of Nefopam group $(34.0 \pm 19.7 \mathrm{ml})$ showed no significant differences compared to Ketorolac group $(30.7 \pm 18.4 \mathrm{ml}$, $P$-value $=0.46$ ).

Conclusion: Nefopam showed a similar efficacy and lower incidence of nausea within $6 \mathrm{~h}$ after the operation to that of ketorolac in PCA. Nefopam may be a useful analgesic drug for the opioid-based PCA after gynecologic surgery. Further evaluation of accurate equivalent dose of nefopam as well as pharmacokinetics of bolus administration is required.
\end{abstract}

Key words: Gynecologic surgery, Nefopam, Oxycodone, Patient-controlled analgesia, Postoperative pain

\section{Introduction}

Postoperative pain can induce postoperative complications such as atelectasis, hypertension, delirium, prolonged hospital stay, and decreased satisfaction of patients. Patient-controlled analgesia (PCA) has been known to decrease pain intensity and postoperative complications more effectively than conventional opioid analgesia [1]. Non-steroidal anti-inflammatory drugs (NSAIDs) have been used in combination with opioids such as fentanyl, morphine, or oxycodone for PCA since they have been known to reduce opioid consumption and opioid-related side effects [2]. However, NSAIDs may affect platelet function which increase bleeding tendency, and induce gastrointestinal side-effects $[3,4]$. Nefopam is a centrally acting analgesic which has been used in many countries since the mid-1970s [5]. Manoir et al. 
[6] suggested that bolus administration of nefopam (every $4 \mathrm{~h}$ for $24 \mathrm{~h}$ ) showed a significant morphine-sparing effect without major side-effects. Even solitary administration of nefopam in PCA provided postoperative analgesia in cardiac surgery [7]. There are no contraindication to combine nefopam and ketorolac. However, we focused that nefopam could be a substitute for NSAIDs in patients who are contraindications and have a difficulty in using NSAIDs. Despite many studies on effects of nefopam, knowledge about nefopam/oxycodone combination for postoperative analgesia is lacking. Therefore, here we investigate the efficacy and side effects of nefopam in comparison with ketorolac in oxycodone PCA after gynecologic surgery.

\section{Methods}

\section{Study design and Ethics approval}

A prospective, randomized and double blind study was conducted at the Department of Anesthesia and Pain Medicine at Pusan National University Hospital, Korea from June to September 2014. This study was approved by the Institutional Review Board for Human Experiments at Pusan University Hospital Medical Research Institute and registered with Clinical Research Information Service which conforms to the World Health Organization International Clinical Trials Registry Platform (WHO-ICTRP); KCT0001236. All patients were provided informed consent.

\section{Subjects}

120 patients, who were admitted for elective gynecologic surgery, ASA class I or II, and aged 18 to 65 years old, were assessed. Patients, who do not qualify for or do not prefer treatment of opioids or NSAIDs, or who have psychological disorder, chronic pain disorder or preoperative administration of drugs including opioids, antidepressants, gabapentin, pregabalin, and carbamazepine, were excluded. Patients, who cannot use numerical rating scale (NRS), who have increased intracranial pressure, renal failure, hepatic failure, or in pregnancy, were also excluded. 105 patients were enrolled in this study.

\section{Treatment}

Patients were divided randomly into two groups using online statistical program "www.randomization.com": Nefopam group (nefopam $1 \mathrm{mg}$ and oxycodone $1 \mathrm{mg}$ per $1 \mathrm{ml}$ in PCA, $n=$ 52) and Ketorolac group (ketorolac $1.5 \mathrm{mg}$ and oxycodone $1 \mathrm{mg}$ per $1 \mathrm{ml}$ in PCA, $n=53$ ). The randomized number were divided into two groups, and we had a random number table before patients were confirmed. Patients were received randomized number in sequence. They were separated into two groups. All patients and anesthesia doctors who participated in the study did not know about in which group patients were during anesthesia and postoperative visit for pain assessment. Anesthesia was standardized. Glycopyrrolate $0.2 \mathrm{mg}$ was intramuscularly injected to all the patients $30 \mathrm{~min}$ before induction of anesthesia. After the patient arrived in the operating room, baseline heart rate, mean arterial blood pressure, and oxygen saturation were measured using a patient monitor. Bispectral index (BIS, XP version 4.1; Aspect Medical Systems, Newton, MA, USA) monitoring was used to measure the depth of anesthesia. Propofol 2 $\mathrm{mg} / \mathrm{kg}$ i.v., rocuronium $0.6 \mathrm{mg} / \mathrm{kg}$ i.v., and remifentanil $0.5 \mu \mathrm{g} / \mathrm{kg} / \mathrm{min}$ i.v. were administered for the induction, and remifentanil and desflurane were used for maintenance. Remifentanil was adjusted to maintain systolic arterial pressure within $20 \%$ of baseline value. An antiemetic (ondansetron $8 \mathrm{mg}$ i.v.) was administered 30 min before the end of surgery. During subcutaneous suture, loading dose of analgesics (nefopam $20 \mathrm{mg}$ and oxycodone $5 \mathrm{mg}$ in Nefopam group, ketorolac $30 \mathrm{mg}$ and oxycodone $5 \mathrm{mg}$ in Ketorolac group) was infused slowly. After the operation, pyridostigmine $10 \mathrm{mg}$ i.v. and glycopyrrolate 0.4 mg i.v. were administered, and patients were transferred to post-anesthesia care unit, and stayed until Aldrete score was greater than 8 . Patients received pain control via PCA device (GemStar ${ }^{\circledR}$ Infusion System, Hospira, IL, USA) with a bolus dose of $1 \mathrm{ml}$, a lock-out interval of $6 \mathrm{~min}$, and a 4 hours limit of $40 \mathrm{ml}$. Nurses in anesthesiology department prepared the drugs for PCA according to the group. Anesthesia doctors did not know patient's group during anesthesia and postoperative visit for pain assessment.

\section{Assessment}

After the operation, a blinded observer assessed the pain using a numeric rating scale (NRS) at rest, infused PCA dose, Ramsay sedation scale at 1, 4, 24, and $48 \mathrm{~h}$. If a patient complained the pain above NRS 5 , we recommended the patient to press the button. There were no other rescue medications. The Ramsay sedation scale was applied to assess the sedation level: 1 = anxious, agitated, or restless; 2 = cooperative, oriented, and tranquil; $3=$ responds to command; $4=$ brisk response to a light glabellar tap or loud auditory stimulus; 5 = sluggish response to a light glabellar tap or loud auditory stimulus; and $6=$ no response to the stimuli. Side-effects such as nausea, vomiting, headache, shivering, pruritus, and delirium were assessed at 6,24 , and $48 \mathrm{~h}$, and satisfaction at $48 \mathrm{~h}$ after the operation. Nausea was classified into three grades: $1=$ mild; 2 = moderate; and 3 = severe. If patients complained nausea above grade $2,4 \mathrm{mg}$ i.v. ondansetron 
was administered. Vomiting was graded into two grades: $1=<4$ times of vomiting; $2=\geq 4$ times of vomiting. Patients were asked to rank their satisfaction according to the following scale: $1=$ very unsatisfactory; 2 = unsatisfactory; 3 = neutral; $4=$ satisfactory; and $5=$ very satisfactory.

\section{Statistical analysis}

The estimated sample size was 50 subjects in each group which was calculated from $\beta$-risk of $80 \%$ at an $a$-level of 0.05 for detecting a difference in $\mathrm{cu}-$ mulative PCA dose $(29 \mathrm{ml}$ vs. $33 \mathrm{ml})$ of at least $4 \mathrm{ml}$ at $48 \mathrm{~h}$ after the operation with the standard deviation of 8.0 for each group in the preliminary test. 120 patients were assessed for study considering $20 \%$ as exclusion rate. Data are expressed as mean \pm SD. The demographic data were compared using the Student's t-test. Preoperative diagnoses, procedures and the incidence of side-effects was compared between two groups using the chi-square test and Mann-Whitney test. The cumulative PCA dose, blood loss and the sedation scores were compared using Mann-Whitney test. The NRS were compared using two-way repeated measures ANOVA. The satisfaction scores of two groups were compared using the chi-square test. A probability of $<0.05$ was considered to be significant. SPSS (21.0 IBM statistics data editor SPSS Inc., Chicago, IL, USA) was used for all statistical analyses.

\section{Results}

Six patients in Ketorolac group and five patients in Nefopam group were excluded and discontinued earlier due to early discharge or intractable nausea (Figure 1). There were no differences in weight, height, age, operation time, preoperative diagnoses, procedure, blood loss, total remifentanil infusion dose, previous emesis history, smoking history, change of hemoglobin and the incidence of transfusion between both groups (Table 1). Nefopam group showed less nausea in $6 \mathrm{~h}$ after the operation $(P$-value $=0.04)$. There were no significant differences in nausea after $6 \mathrm{~h}$ after the operation, vomiting, headache, shivering, pruritus, delirium, and satisfaction between the two groups (Table 2, Table 3). There were no significant differences in NRS and accumulated PCA dose between both groups. At $48 \mathrm{~h}$ after operation, the infused PCA volume of Nefopam group (34.0 $\pm 19.72 \mathrm{ml}$ ) was not significantly different from that of Ketorolac group $(30.7 \pm 18.39 \mathrm{ml}, P$-value $=0.457)$. Both groups showed a decrease in pain as time went by (Figure 2). Ramsay sedation scale of Nefopam group was also not significantly different from that of Ketorolac group (Figure 3).
Table 1. Demographic Data.

\begin{tabular}{|c|c|c|c|}
\hline & Nefopam & Ketorolac & $P$-value \\
\hline Weight (kg) & $58.4(6.9)$ & $58.36(9.3)$ & 0.05 \\
\hline Height (cm) & $159.33(5.4)$ & $158.21(5.4)$ & 0.44 \\
\hline Age (yrs.) & 43.25 (11.5) & $41.81(13.3)$ & 0.24 \\
\hline Operation time (min) & $127(42.0)$ & $125.6(41.6)$ & 0.79 \\
\hline \multicolumn{4}{|l|}{ Preoperative diagnoses } \\
\hline Ovarian mass & 26 & 21 & 0.29 \\
\hline Myoma & 26 & 32 & \\
\hline $\begin{array}{l}\text { Type of surgery (laparosco- } \\
\text { py/laparotomy) }\end{array}$ & $31 / 21$ & $29 / 24$ & 0.61 \\
\hline $\begin{array}{l}\text { Laparoscopic ovarian cystec- } \\
\text { tomy }\end{array}$ & 26 & 21 & 0.51 \\
\hline $\begin{array}{l}\text { Total laparoscopic hysterec- } \\
\text { tomy }\end{array}$ & 5 & 8 & \\
\hline $\begin{array}{l}\text { Total abdominal hysterecto- } \\
\text { my }\end{array}$ & 13 & 18 & \\
\hline $\begin{array}{l}\text { Abdominal } \\
\text { myomectomy }\end{array}$ & 8 & 6 & \\
\hline Blood loss (ml) & $351.4(270.4)$ & $281.9(260.7)$ & 0.19 \\
\hline $\begin{array}{l}\text { Total infused remifentanil dose } \\
(\mathrm{mcg})\end{array}$ & $489.5(323.6)$ & 427 (209.6) & 0.07 \\
\hline $\begin{array}{l}\text { History of motion sickness or } \\
\text { PONV (n) }\end{array}$ & 2 & 4 & 0.33 \\
\hline Smoking history (n) & 0 & 2 & 0.22 \\
\hline $\begin{array}{l}\text { Change of } \mathrm{Hb}(\mathrm{mg} / \mathrm{dl}) \\
\text { (POD1 } \mathrm{Hb}-\mathrm{POD} 2 \mathrm{Hb})\end{array}$ & $1.3(0.9)$ & $1.2(1.0)$ & 0.76 \\
\hline Postoperative transfusion (n) & 1 & 2 & 1.00 \\
\hline
\end{tabular}

There are no differences in weight, height, age, operation time, preoperative diagnoses, procedures, blood loss, total infusion dose of remifentanil, history of motion sickness, smoking, change of hemoglobin $(\mathrm{Hb})$ and the incidence of transfusion between both groups. Data are expressed as mean value and standard deviation (SD).

Table 2. Side Effects of Patient-Controlled Analgesia.

\begin{tabular}{|c|c|c|c|c|c|c|}
\hline & & & Nefopam & Ketorolac & Total & $P$-value \\
\hline \multirow[t]{8}{*}{ Nausea } & $<6$ hours & 1 & 11 & 19 & 30 & 0.04 \\
\hline & & 2 & 2 & 4 & 6 & \\
\hline & & 3 & 0 & 1 & 1 & \\
\hline & 6-24 hours & 1 & 7 & 12 & 19 & 0.31 \\
\hline & & 2 & 2 & 1 & 3 & \\
\hline & & 3 & 1 & 1 & 2 & \\
\hline & $>24$ hours & 1 & 2 & 1 & 3 & 1.00 \\
\hline & & 2 & 2 & 2 & 4 & \\
\hline \multirow[t]{2}{*}{ Vomiting } & & 1 & 0 & 1 & 1 & 1.00 \\
\hline & & 2 & 0 & 1 & 1 & \\
\hline Headache & & & 2 & 3 & 5 & 0.67 \\
\hline Shivering & & & 3 & 4 & 7 & 0.72 \\
\hline Pruritus & & & 1 & 3 & 4 & 0.36 \\
\hline Delirium & & & 0 & 0 & 0 & 1.00 \\
\hline
\end{tabular}

Table 3. Satisfaction of Patients on Patient-Controlled Analgesia.

\begin{tabular}{llll}
\hline & Nefopam & Ketorolac & $P$-value \\
\hline Very satisfied & $16(34)$ & $8(17)$ & 0.14 \\
Somewhat satisfied & $24(51.1)$ & $28(59.6)$ & \\
Neither satisfied nor dissat- & $7(14.9)$ & $9(19.1)$ & \\
isfied & & & \\
Somewhat dissatisfied & $0(0)$ & $2(4.3)$ & \\
Very dissatisfied & $0(0)$ & $0(0)$ & \\
\hline
\end{tabular}

There is no significant difference on satisfaction between both groups. 


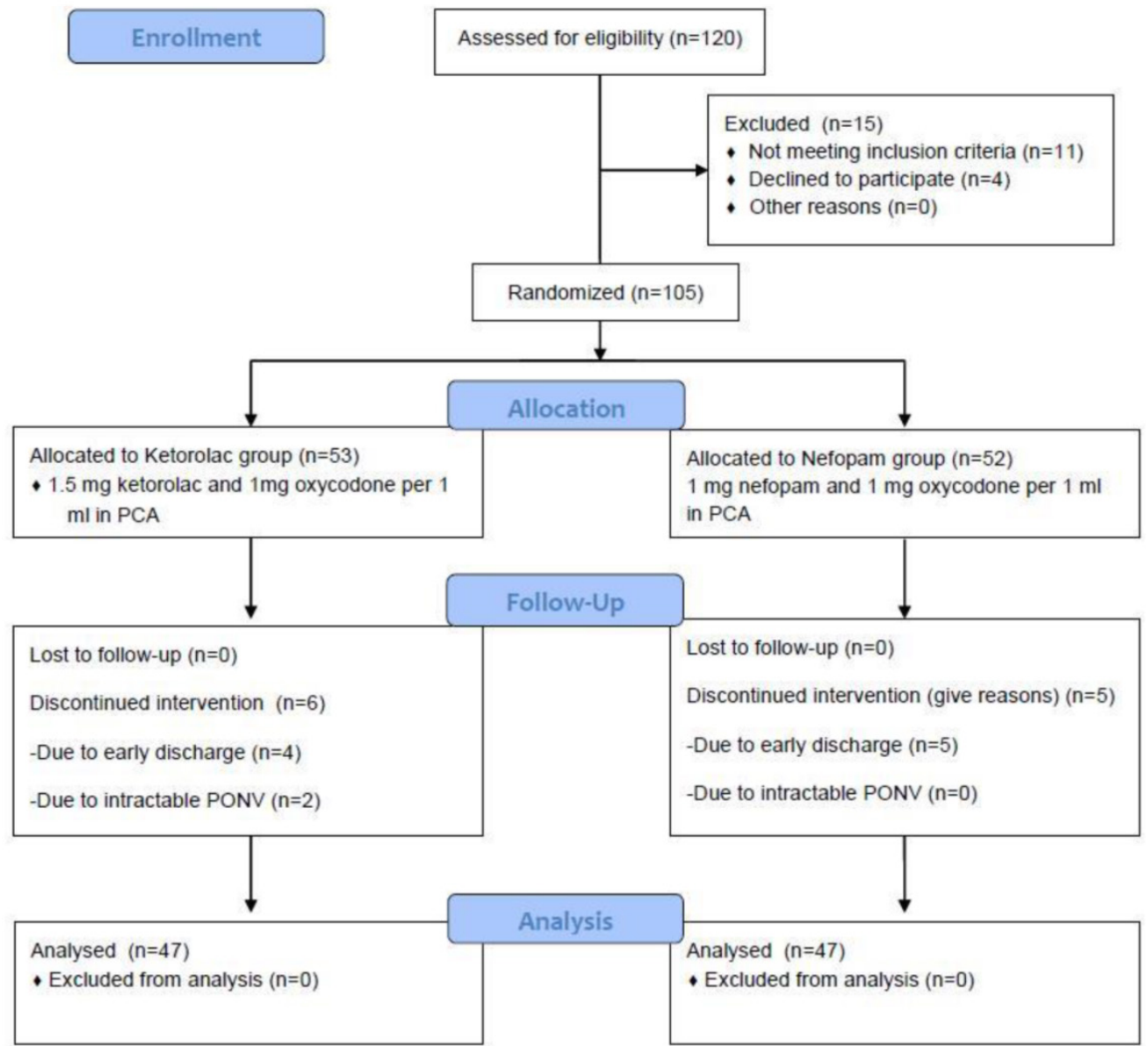

Figure 1. Study flow chart with individual causes of study interruptions and dropouts. The flow chart of this study was according to the CONSORT Statement. There was no significant difference on rate of dropouts between both groups. ( $P$-value $=0.78$ )

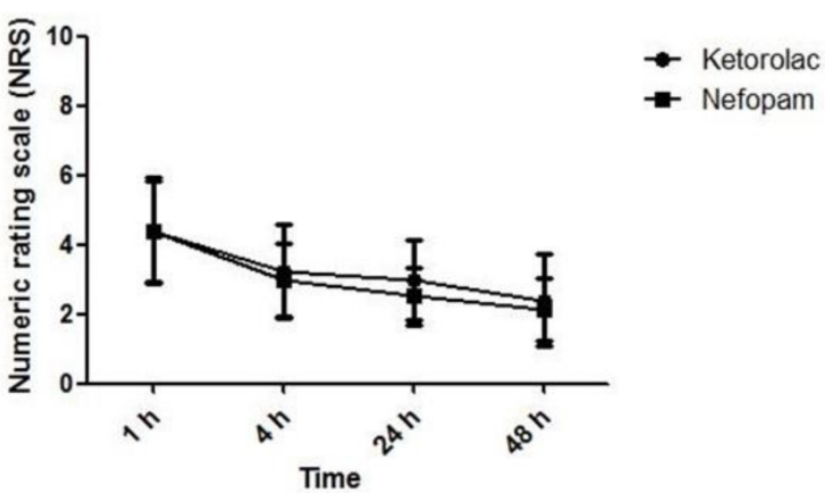

Figure 2. The NRS of pain intensity was assessed at $1,4,24$ and $48 \mathrm{~h}$ after the operation. There is no significant difference between both groups. Both groups show a decrease in pain as the time passed. Data are expressed as mean $\pm S D$.

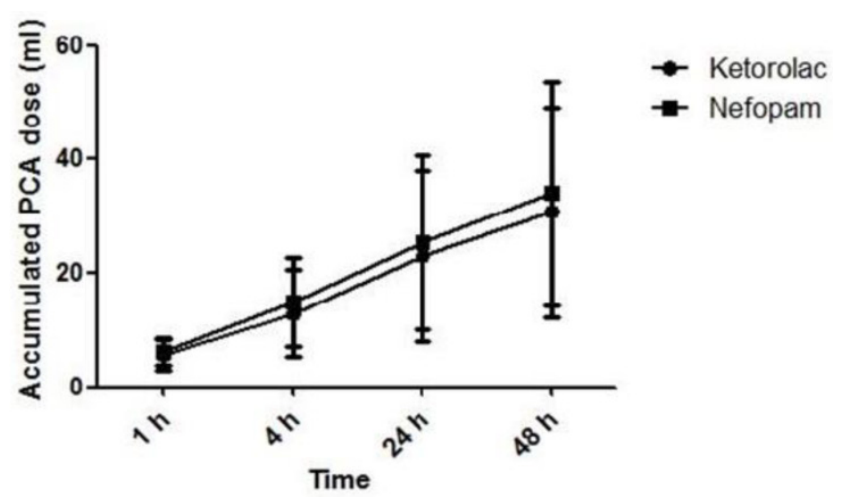

Figure 3. The accumulated PCA dose was assessed at 1, 4, 24 and $48 \mathrm{~h}$ after the operation. There is no significant difference between both groups. Data are expressed as mean \pm SD. 


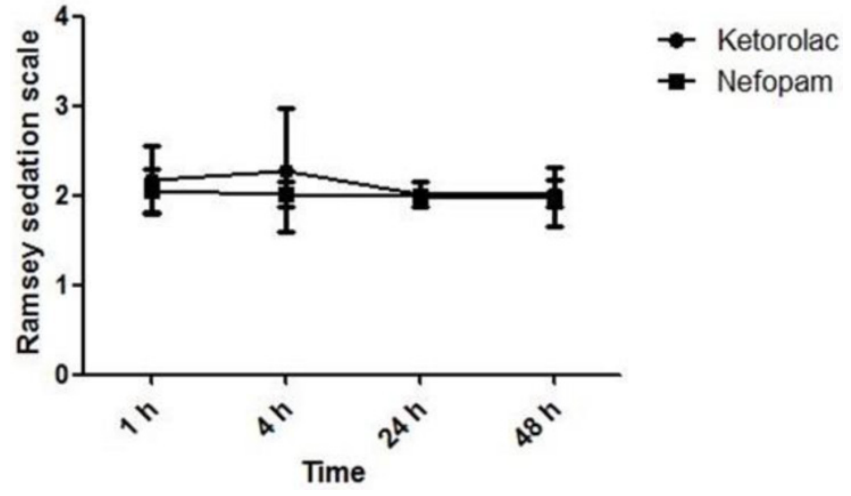

Figure 4. Ramsey sedation scale was assessed at 1, 4, 24 and $48 \mathrm{~h}$ after the operation. There is no significant difference between both groups. Data are expressed as mean \pm SD.

\section{Discussion}

Many medical centers have applied opioids, NSAIDs, antiemetics and other analgesics for i.v. PCA. Opioids are effective analgesics for the management of postoperative pain, but the use of opioids has been limited by adverse effects such as postoperative bowel ileus, drowsiness, nausea, vomiting, constipation, urinary retention, shivering, acute tolerance, respiratory depression, and delirium [8-12]. Gynecologic surgery is known to induce severe nausea [13]. In the previous study, we observed that oxycodone PCA induces more nausea than fentanyl PCA in acute period after the operation [14]. To reduce an opioid consumption, it is necessary to carry on further studies on adjuvant analgesics.

There have been a lot of alternative ways to manage postoperative pain including analgesic adjuvants such as capsaicin, ketamine, gabapentin, dexmedetomidine, and transformed mode in PCA [15]. NSAIDs have been known to increase the efficiency and decrease the opioid-related adverse effects in opioid-based PCA. However, NSAIDs have limitations as PCA adjuvants. First, NSAIDs may cause digestive ulcer and bleeding [16]. Second, NSAIDs are the drugs most commonly involved in hypersensitivity drug reactions [17]. Third, NSAIDs are cleared from blood stream by kidney, but patients over 65 years old or with renal insufficiency may have a kidney injury [18]. Patients who have cardiovascular risk are also known to be assessed carefully before the treatment with NSAIDs [19]. Therefore, alternative adjuvant analgesics are still required. Nefopam showed significant opioid-sparing effects in combination with morphine PCA after orthopedic surgery [6]. The combination of nefopam and paracetamol provided synergistic analgesic effects on mild and moderate pain surgery [20]. There have also been several studies about the analgesic effects of nefopam on neuropathic pain [21]. Nefopam is a centrally acting benzoxazocine analgesic, and is a cyclized analogue of diphenhydramine. Nefopam could be related neurologic side effects such as delirium, confusion and seizure in old age $[22,23]$. But this study excluded patients who have psychological disorder, old age, or preoperative administration of drugs that have an effect on patient's neurology. There was no complication such as delirium in the current study.

We compared the efficacy and side-effects of nefopam/oxycodone and ketorolac/oxycodone combination. However, we did not consider the pharmacokinetic factors of drugs, and they have a different onset time and duration. Therefore, we cannot confirm the accurate efficacy and potency of both analgesics at the same time. Further evaluation of accurate equivalent dose of ketorolac and nefopam as well as pharmacokinetics of bolus administration is required. It could be effective method if NSAIDs, nefopam and opioid are combined while patients are not contraindications and do not have any risk of NSAIDs-related side effects. If we have a further evaluation for pharmacologic interactions and metabolism of both drugs, it could be a good study for opioid minization in PCA.

This study showed that nefopam has a comparable analgesic effect in the pain management after gynecologic surgery as compared to ketorolac. The frequency of nausea within $6 \mathrm{~h}$ after the operation in Nefopam group was lower than that in Ketorolac group. Considering that many patients discontinue PCA due to severe nausea, application of nefopam for oxycodone-based PCA would be great advantage for postoperative pain management. Nefopam would be an adequate substitute for NSAIDs, especially in high risk patients using NSAIDs or opioid alone.

\section{Conflicts of Interest}

The authors declare that there are no conflicts of interest.

\section{References}

1. Hudcova J, McNicol E, Quah C, et al. Patient controlled opioid analgesia versus conventional opioid analgesia for postoperative pain. Cochrane Database Syst Rev 2006;: CD003348.

2. Cepeda MS, Carr DB, Miranda N, et al. Comparison of morphine, ketorolac, and their combination for postoperative pain: results from a large, randomized, double-blind trial. Anesthesiology 2005; 103: 1225-32.

3. Dordoni PL, Della Ventura M, Stefanelli A, et al. Effect of ketorolac, ketoprofen and nefopam on platelet function. Anaesthesia 1994; 49: 1046-9.

4. Klein M. Postoperative non-steroidal anti-inflammatory drugs and colorectal anastomotic leakage. NSAIDs and anastomotic leakage. Dan Med J 2012; 59: B4420.

5. Evans MS, Lysakowski C, Tramèr MR. Nefopam for the prevention of postoperative pain: quantitative systematic review. Br J Anaesth 2008; 101: 610-7.

6. Du Manoir B, Aubrun F, Langlois M, et al. Randomized prospective study of the analgesic effect of nefopam after orthopaedic surgery. Br J Anaesth 2003; 91: 836-41.

7. Kim K, Kim WJ, Choi DK, et al. The analgesic efficacy and safety of nefopam in patient-controlled analgesia after cardiac surgery: A randomized, double-blind, prospective study. J Int Med Res 2014; 42: 684-92. 
8. Koo KC, Yoon YE, Chung BH, et al. Analgesic opioid dose is an important indicator of postoperative ileus following radical cystectomy with ileal conduit: experience in the robotic surgery era. Yonsei Med J 2014; 55: 1359-65.

9. McNicol E, Horowicz-Mehler N, Fisk RA, et al. Management of opioid side effects in cancer-related and chronic noncancer pain: a systematic review. J Pain 2003; 4: 231-56.

10. Remy C, Marret E, Bonnet F. Effects of acetaminophen on morphine side-effects and consumption after major surgery: meta-analysis of randomized controlled trials. Br J Anaesth 2005; 94: 505-13.

11. Maund E, McDaid C, Rice S, et al. Paracetamol and selective and non-selective non-steroidal anti-inflammatory drugs for the reduction in morphine-related side-effects after major surgery: a systematic review. Br J Anaesth 2011; 106: 292-7.

12. Jitpakdee T, Mandee S. Strategies for preventing side effects of systemic opioid in postoperative pediatric patients. Paediatr Anaesth 2014; 24: 561-8.

13. Kenny GN, Oates JD, Leeser J, et al. Efficacy of orally administered ondansetron in the prevention of postoperative nausea and vomiting: a dose ranging study. Br J Anaesth 1992; 68: 466-70.

14. Hwang BY, Kwon JY, Kim E, et al. Oxycodone vs. fentanyl patient-controlled analgesia after laparoscopic cholecystectomy. Int J Med Sci 2014; 11: 658-62.

15. Vadivelu N, Mitra S, Narayan D. Recent advances in postoperative pain management. Yale J Biol Med 2010; 83: 11-25.

16. Dib RA, Chinzon D, Fontes LH, et al. Ulcer and bleeding complications and their relationship with dyspeptic symptoms in NSAIDs users: a transversal multicenter study. Scand J Gastroenterol 2014; 49: 785-9.

17. Torres MJ, Barrionuevo E, Kowalski M, et al. Hypersensitivity reactions to nonsteroidal anti-inflammatory drugs. Immunol Allergy Clin North Am 2014; 34: 507-24, vii-viii.

18. Perazella MA, Buller GK. NSAID nephrotoxicity revisited: acute renal failure due to parenteral ketorolac. South Med J 1993; 86: 1421-4.

19. Amer M, Bead VR, Bathon J, et al. Use of nonsteroidal anti-inflammatory drugs in patients with cardiovascular disease: a cautionary tale. Cardiol Rev 2010; 18: 204-12.

20. Van Elstraete AC, Sitbon P. Median effective dose (ED50) of paracetamol and nefopam for postoperative pain: isobolographic analysis of their antinociceptive interaction. Minerva Anestesiol 2013; 79: 232-9.

21. Dam LJ, Hai L, Ha YM. Role of the 5-HT(7) receptor in the effects of intrathecal nefopam in neuropathic pain in rats. Neurosci Lett 2014; 566: 50-4.

22. Lin $\mathrm{KH}$, Chen YJ, Wei CF, et al. Prolonged withdrawal delirium in concomitant diphenhydramine and nefopam dependence: A case report. Prog Neuropsychopharmacol Biol Psychiatry. 2010; 34: 705-6.

23. Park YS, Kim YB, Kim JM. Status epilepticus caused by nefopam. J Korean Neurosurg Soc. 2014; 56: 448-50. 